\title{
T-cell regulation during viral and nonviral asthma exacerbations
}

\section{To the Editor:}

Asthma is a common chronic inflammatory disease of the airways characterized by recurrent episodes of airway inflammation and following cycles of tissue repair and regeneration. ${ }^{1}$ Asthma exacerbations are defined as episodes of progressive increase in shortness of breath, cough, wheezing, and chest tightness, or a combination of these symptoms, accompanied by decreases in expiratory airflow that can be quantified by measurement of lung function.

Factors contributing to exacerbations of asthma symptoms include respiratory infections (viral, bacterial, and atypical), allergens (aeroallergens and food allergens), exposures (occupational allergens and drugs), and miscellaneous factors $(\beta$-adrenergic receptor polymorphisms and nonrespiratory factors). ${ }^{2}$ The immune mechanisms underlying acute episodes of asthma are poorly understood, and whether factors contributing to asthma exacerbations for different reasons engage distinct immune pathways has been studied in the present study.

In patients with asthma, airway inflammation is driven by $\mathrm{T}$ cells, with the most important role attributed to $\mathrm{T}_{\mathrm{H}} 2$ cells and their cytokines. There is growing evidence that not only $\mathrm{T}_{\mathrm{H}} 2$ cells have been associated with the development and progression of asthma but also $\mathrm{T}_{\mathrm{H}} 17$ cells might be involved by supporting the recruitment and survival of neutrophils, which were detected in sputum of subjects with asthma exacerbations and severe persistent asthma. ${ }^{1}$ Furthermore, data on the function of regulatory $\mathrm{T}$ (Treg) cells in asthma in humans are largely incomplete and quite inconsistent, although their role in allergen tolerance and allergen-specific immunotherapy has been intensively studied. ${ }^{3}$

To address these questions in a clinical setting, we used multicolor flow cytometry for the evaluation of phenotypical changes in $\mathrm{CD}^{+}{ }^{+} \mathrm{T}$ cells in subjects with asthma during acute episodes and stable asthma compared with the control group. The clinical characteristics of subjects are summarized in Table E1 in this article's Online Repository at www.jacionline.org. Viruses were determined in the induced sputum during exacerbation. Rhinovirus $(\mathrm{n}=6)$, metapneumovirus $(\mathrm{n}=1)$, parainfluenza-2 virus and metapneumovirus $(n=1)$, and parainfluenza-1 and respiratory syncytial virus $(n=1)$ were identified in 9 virus-induced asthma exacerbation cases.

Our data demonstrate that Treg cells analyzed according to the gating of $\mathrm{CD}^{+} \mathrm{CD} 4^{+} \mathrm{CD} 25^{+} \mathrm{CD} 127^{-} \mathrm{FOXP}^{+}$and Helios ${ }^{+}$ cells (Fig $1, A$ ) exhibit a major change during asthma exacerbations. Higher numbers of Treg cells in peripheral blood were found in subjects with stable asthma than in healthy controls. In contrast, during asthma exacerbations, the number of Treg cells was significantly reduced than during stable asthma (Fig 1, B). In addition, the frequency of Treg cells positively correlated 


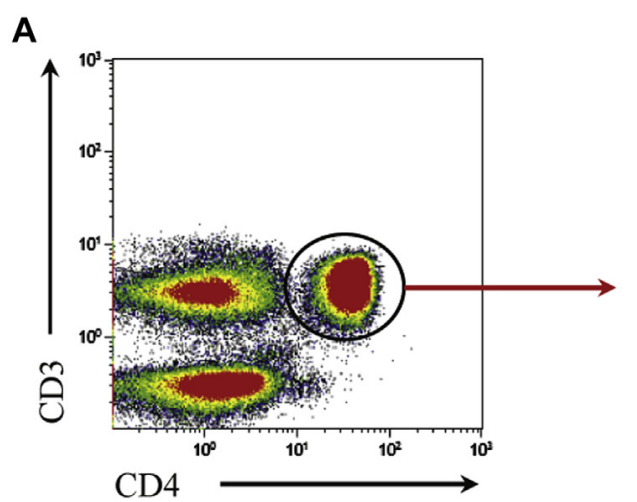

B

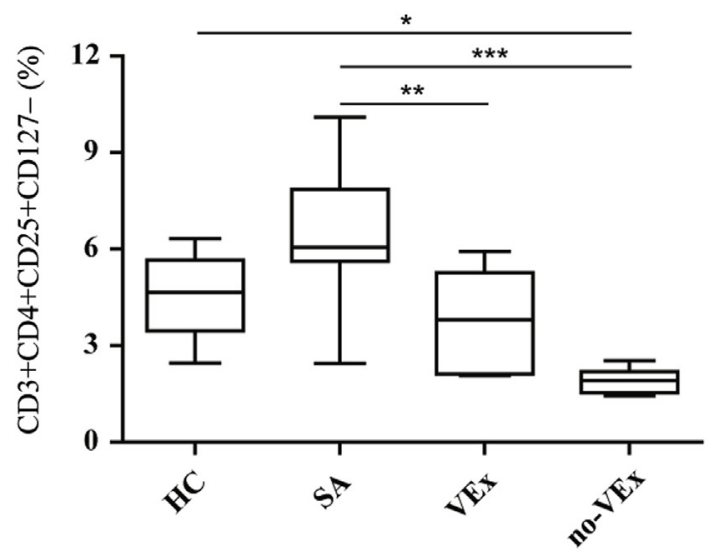

D

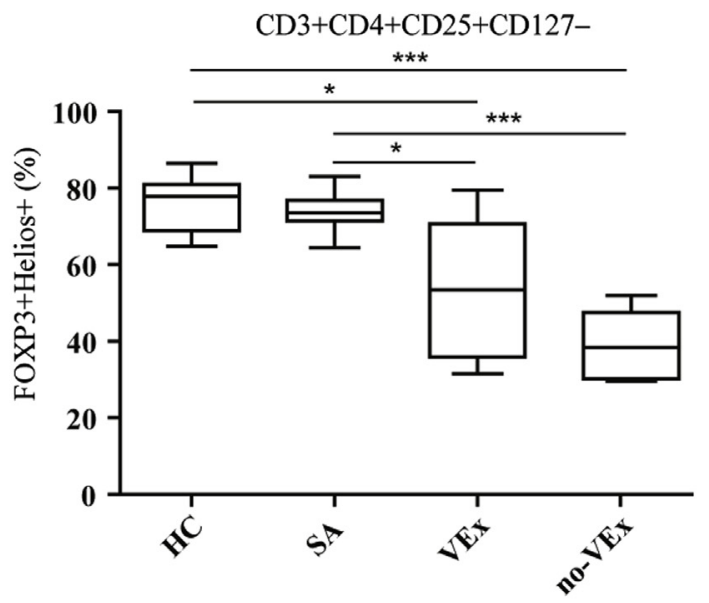

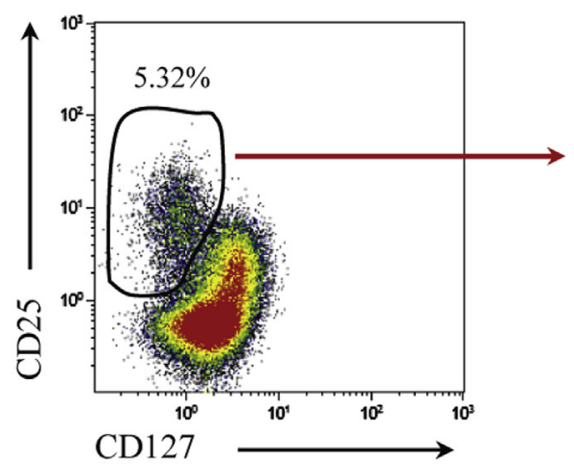

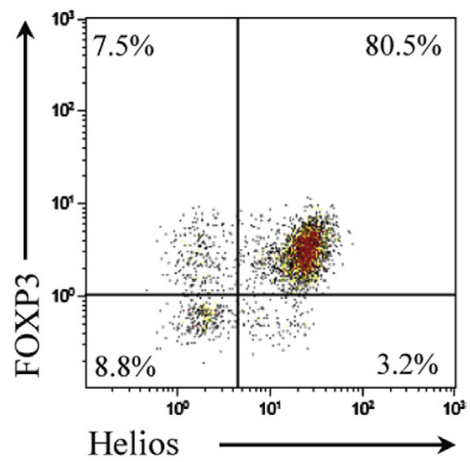

C

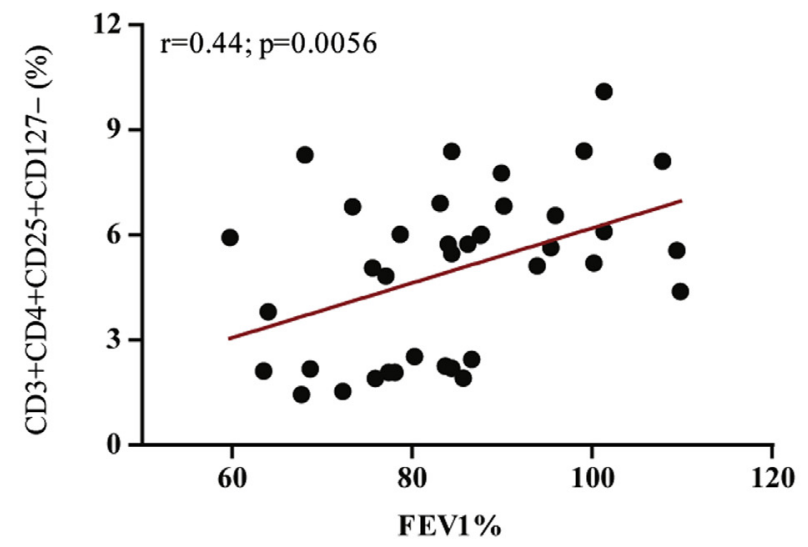

E

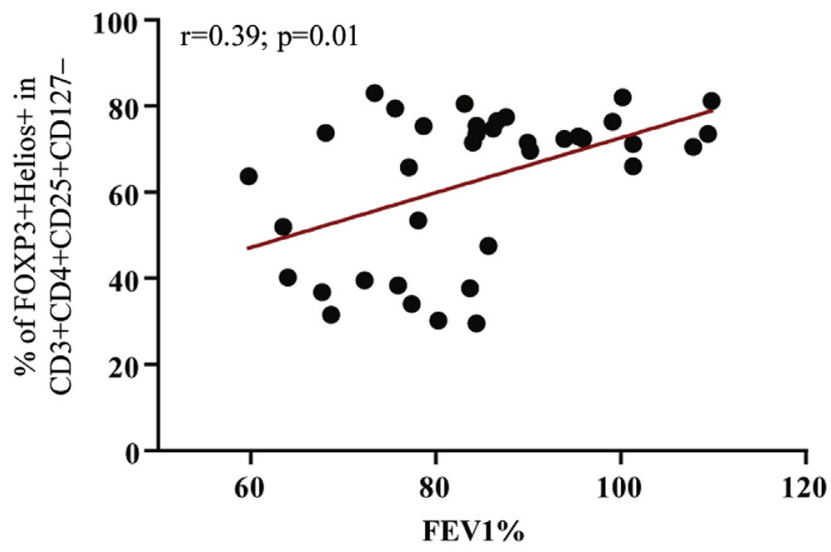

FIG 1. Decreased frequency of Treg cells during asthma exacerbations. A, Treg cells were identified in $\mathrm{CD}^{+} \mathrm{CD}^{+}{ }^{+}$T-cell gate on the basis of the expression of CD25 and CD127 as well as intracellular FOXP3 and Helios. B, The percentage of $\mathrm{CD}^{+} \mathrm{CD}^{+} \mathrm{CD} 25^{+} \mathrm{CD} 127^{-}$(Treg cells) was significantly decreased in asthma exacerbations. C, The frequency of Treg cells positively correlates with FEV $_{1} \%$. During asthma exacerbations, the percentage of FOXP3 ${ }^{+}$Helios $^{+}$Treg cells was reduced (D) and was positively correlated with $\mathrm{FEV}_{1} \%$ (E). $H C$, Healthy control; no-VEx, nonviral exacerbated asthma; $S A$, stable asthma; VEx, viral exacerbated asthma.

with predicted percentage of $\mathrm{FEV}_{1}\left(\mathrm{FEV}_{1} \%\right)(\mathrm{Fig} 1, C)$. Increased frequency of Treg cells in subjects with stable asthma could be due to corticosteroid treatment, as previously reported in adult subjects with asthma. ${ }^{4}$ The speed of kinetics of decrease and recovery of Treg cells during asthma exacerbations and stabilization is difficult to predict without a longitudinal study.
The evaluation of migratory properties of Treg cells is limited by lack of availability of suitable markers for homing to lungs. ${ }^{5}$ In the present study, we used CCR7 as a marker for migratory properties of Treg cells toward central lymphatic organs as a marker for exit from peripheral organs (see Fig E1 in this article's Online Repository at www.jacionline.org). ${ }^{5}$ These data show a 


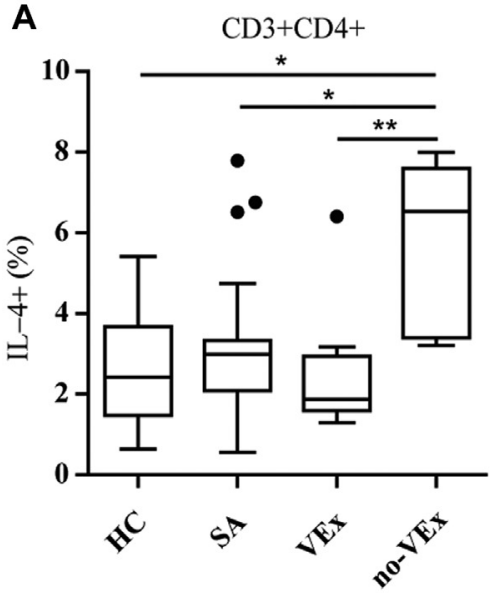

D

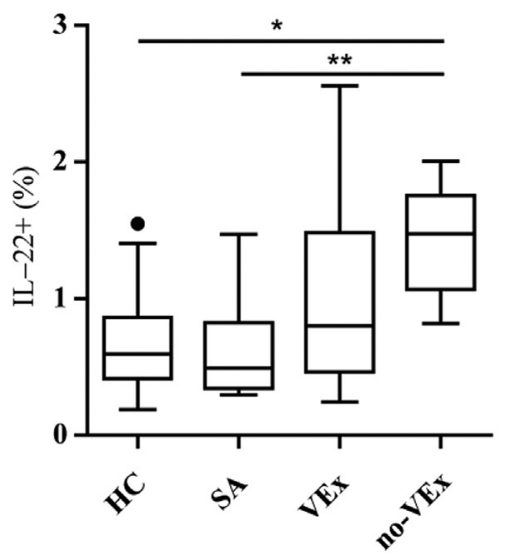

B

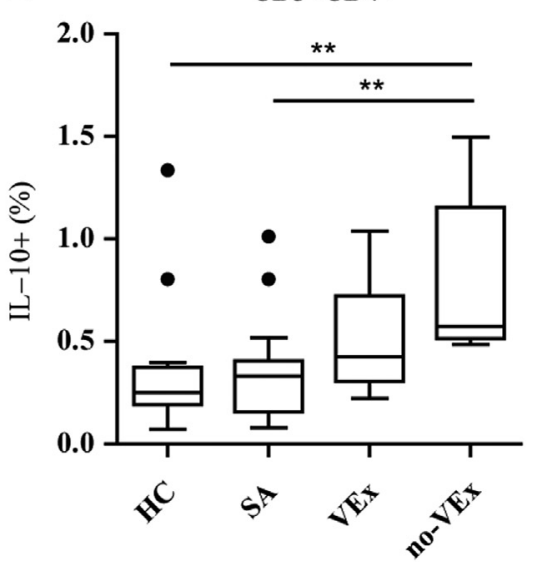

E

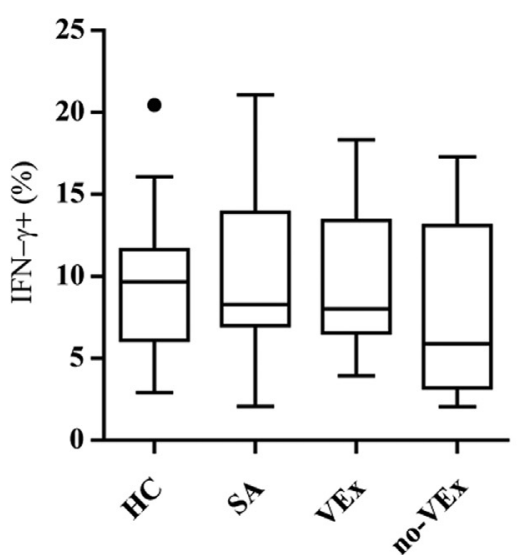

C

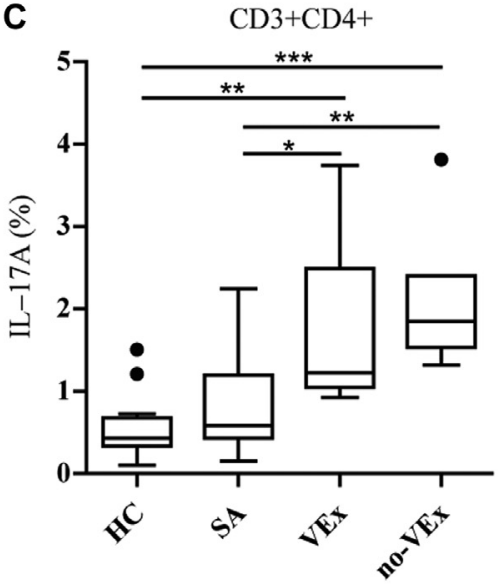

FIG 2. Distinct cytokine profile of $\mathrm{CD} 3^{+} \mathrm{CD} 4^{+} \mathrm{T}$ cells in asthma exacerbations. A, IL-4-producing $\mathrm{CD} 3^{+} \mathrm{CD} 4^{+}$ $\mathrm{T}$ cells. B, IL-10-producing $\mathrm{CD} 3^{+} \mathrm{CD} 4^{+} \mathrm{T}$ cells. C, IL-17A-producing $\mathrm{CD} 3^{+} \mathrm{CD} 4^{+} \mathrm{T}$ cells. D, IL-22-producing $\mathrm{CD}^{+}{ }^{+} \mathrm{CD} 4^{+} \mathrm{T}$ cells. E, IFN- $\gamma$-producing $\mathrm{CD} 3^{+} \mathrm{CD} 4^{+}$T cells. $\mathrm{HC}$, Healthy control; no-VEx, nonviral exacerbated asthma; $S A$, stable asthma; VEx, viral exacerbated asthma. ${ }^{*} P \leq .05,{ }^{*} P \leq .01$, and ${ }^{*} *{ }^{*} \leq .001$.

significantly higher frequency of $\mathrm{CCR} 7^{+}$Treg cells in subjects with stable asthma than in healthy controls and both exacerbation groups, whereas during asthma exacerbation reduced frequency of $\mathrm{CCR}^{-}$Treg cells was observed probably because of sequestration of $\mathrm{CCR} 7^{+}$cells in the central lymphatic organs. Conclusive data on a specific recruitment of Treg cells into or out of the airway tissue requires further studies, which also enumerate them directly in the lungs.

For the in-depth analysis of Treg cells, forkhead box P3 (FOXP3) and Helios expression on $\mathrm{CD} 25^{+} \mathrm{CD} 127^{-}$Treg cells was studied. FOXP3 determines the development as well as the immunosuppressive activity of Treg cells. Helios is a member of Ikaros family transcription factors, which are involved in the control of gene transcription through chromatin remodeling. ${ }^{6}$ In addition, it was recently demonstrated that these 2 transcription factors interact and potentiate each other, such as Helios upregulates FOXP3 expression by binding to the promoter of FOXP3. ${ }^{6}$

According to the expression of FOXP3 and Helios, 4 distinct subsets of Treg cells were discriminated (see Fig E2, $A$ and $B$, in this article's Online Repository at www.jacionline.org). In healthy donors and subjects with stable asthma, most of the Treg cells were FOXP $^{+}{ }^{+}$Helios ${ }^{+}$. In contrast, during acute asthma episodes, decreased frequency of Treg cells with both FOXP $3^{+} \mathrm{Helios}^{+}$ expression was observed than in subjects with stable asthma and the control group (Fig 1,D). As observed in $\mathrm{CD} 4{ }^{+} \mathrm{CD} 25^{+} \mathrm{CD} 127^{-}$ Treg cells, the frequency of Treg cells expressing both FOXP3 and Helios positively correlated with $\mathrm{FEV}_{1} \%$ (Fig 1,E).

The pattern of single or coexpression of FOXP3 and Helios by Treg cells showed interesting insights into the expression of these transcription factors on Treg cells (Fig E2). During asthma exacerbations, the frequency of Treg cells expressing both transcription factors was reduced. In addition, the expression of both FOXP3 and Helios positively correlated with $\mathrm{FEV}_{1} \%$ because of a very high correlation of these 2 transcription factors with each other (see Fig E3, $A$ and $B$, in this article's Online Repository at www.jacionline.org). Interestingly, Treg cells with the phenotype of $\mathrm{CD} 4{ }^{+} \mathrm{CD} 25^{+} \mathrm{CD} 127^{-}$, which are FOXP $^{+}{ }^{\text {, but Helios }}{ }^{-}$as well as both $\mathrm{FOXP}^{-}$and Helios ${ }^{-}$cells have expanded in acute asthma episodes, and both subsets showed a negative correlation with $\mathrm{FEV}_{1} \%$.

To further characterize the $\mathrm{CD}^{+}{ }^{+} \mathrm{CD} 4{ }^{+}$T cells, the production of $\mathrm{T}_{\mathrm{H}}$ cell lineage-specific prototype cytokines IL-4, IL-10, IL-17A, IL-22, and IFN- $\gamma$ was evaluated (Fig 2; see Fig E4, $A$, in this article's Online Repository at www.jacionline.org). The data demonstrated 
distinct cytokine expression patterns between viral and nonviral asthma exacerbations. Asthma exacerbations triggered by a nonviral factor, most commonly an allergen, were characterized with increased frequency of IL-4-producing $\mathrm{CD} 3{ }^{+} \mathrm{CD} 4{ }^{+} \mathrm{T}$ cells (Fig 2, A); however, the frequency of that population did not correlate with $\mathrm{FEV}_{1} \%$ (see Fig E5, $A$, in this article's Online Repository at www.jacionline.org). IL-4 in combination with other $\mathrm{T}_{\mathrm{H}}$ 2-related cytokines, such as IL-5 and IL-13, are involved in the development of pathophysiological features of asthma and allergic inflammation. ${ }^{1,7}$ In addition, increased numbers of IL-10 producing $\mathrm{CD} 3{ }^{+} \mathrm{CD} 4{ }^{+} \mathrm{T}$ cells were detected in those with nonvirus asthma exacerbations than in healthy controls and subjects with stable asthma (Fig 2, B). Interestingly, a negative correlation was found between IL-10- producing $\mathrm{CD}^{+}{ }^{+} \mathrm{CD}^{+}{ }^{+} \mathrm{T}$ cells and $\mathrm{FEV}_{1} \%$ (Fig $\mathrm{E} 5, B)$. IL-17A expression in $\mathrm{CD} 4^{+} \mathrm{T}$ cells represented a peripheral marker of asthma exacerbation. Both viral and nonviral acute asthma episodes were strongly associated with increased percentage of IL-17A-producing $\mathrm{CD}^{+} \mathrm{CD}^{+} \mathrm{T}$ cells (Fig 2, C), which showed a negative correlation with $\mathrm{FEV}_{1} \%$ (Fig E5, C). IL-17A induces the production of proinflammatory cytokines and chemokines by airway epithelial cells, fibroblasts, and other cell types, which plays a role in the influx of neutrophils and macrophages to the site of inflammation, and their excessive activation leading to tissue damage. ${ }^{1,7,8}$ The induction of IL-22-producing $\mathrm{CD}^{+}{ }^{+} \mathrm{CD} 4{ }^{+} \mathrm{T}$ cells was also identified in asthma exacerbations triggered by a nonviral factor (Fig 2,D), without showing any correlation with $\mathrm{FEV}_{1} \%$ (Fig E5, D). The percentage of IFN$\gamma$-producing $\mathrm{T}$ cells was similar in all groups (Fig E5, E) and did not correlate with $\mathrm{FEV}_{1} \%$ (Fig E5, E).

In addition to single cytokine expression, our data demonstrate increased frequency of $\mathrm{CD} 4^{+} \mathrm{T}$ cells with a coexpression phenotype of $\mathrm{IL}-17 \mathrm{~A}^{+} \mathrm{IL}-10^{+}, \mathrm{IL}-4^{+} \mathrm{IL}-10^{+}, \mathrm{IL}^{+}{ }^{+} \mathrm{IL}_{-17}{ }^{+}$, $\mathrm{IL}-4^{+} \mathrm{IL}-22^{+}, \mathrm{IL}-17 \mathrm{~A}^{+} \mathrm{IL}-22^{+}$, and $\mathrm{IL}-22^{+} \mathrm{IL}-10^{+}$in nonviral asthma exacerbations, suggesting a general activation of effector cytokines in $\mathrm{CD}^{+}{ }^{+} \mathrm{T}$ cells (see Fig E6 in this article's Online Repository at www.jacionline.org). In contrast to IL-17A, IL-22 exhibits proinflammatory, anti-inflammatory properties as well as tissue regenerative features. ${ }^{7,8}$ It might be assumed that the simultaneous production of IL-22 and IL-17A is responsible for overcoming the tissue damage resulting from the ongoing inflammatory process. IL-22 is an IL-10 family cytokine member and plays an important role in mucosal immunity. The role of IL-22-producing $\mathrm{T}$ cells in bronchial asthma in humans is unknown. ${ }^{8}$ Interestingly, increased levels of IL-22 in the serum of subjects with asthma have been reported. ${ }^{8}$ Furthermore, studies in animal models have demonstrated an involvement of IL-22 in regulation of the infiltration of eosinophils to the airways. ${ }^{9}$ In addition, it may be involved in the stabilization of lung epithelial integrity and homeostasis. However, further studies are required to clarify the role of $\mathrm{T}_{\mathrm{H}} 22$ cells in asthma and their exacerbations. Individuals treated with systemic corticosteroids showed heterogeneity in the populations of effector and regulatory T-cell subsets in the periphery, and it requires further studies for in-depth analyses (see Fig E7 in this article's Online Repository at www.jacionline.org).

In conclusion, our data demonstrate that multicolor flow cytometry represents a relatively rapid tool to investigate peripheral blood lineage-specific CD ${ }^{+}$T-cell characterization that may open a new window for the identification of the etiology of asthma exacerbations. Distinct immune activation and immune regulation pathways were demonstrated in exacerbations due to viral or nonviral etiology. Longitudinal studies are required for better understanding of immune response associated with asthma exacerbations. The knowledge of the dynamics of changes in peripheral blood $\mathrm{T}$ cells may allow the development of rapid tests for cellular diagnosis of asthma exacerbations.

$$
\begin{array}{r}
\text { Agnieszka S. Wegrzyn, } P h D^{a, b} \\
\text { Bogdan Jakiela, } P h D^{c} \\
\text { Beate Rückert, Sci Tec }{ }^{a, b} \\
\text { Marek Jutel, } M D^{d} \\
\text { Mübeccel Akdis, MD, PhD } D^{a, b} \\
\text { Marek Sanak, MD, } P h D^{c} \\
\text { Cezmi A. Akdis, } M D^{a, b}
\end{array}
$$

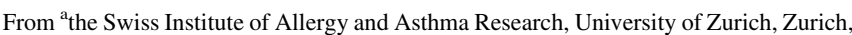
Switzerland; ${ }^{b}$ the Christine Kühne-Center for Allergy Research and Education, Davos, Switzerland; ${ }^{c}$ the Department of Internal Medicine, Jagiellonian University, Krakow, Poland; and the Department of Clinical Immunology, Wroclaw Medical University, Wroclaw, Poland. E-mail: wegrzyn.as@gmail.com. Or: akdisac@siaf uzh.ch.

The authors' laboratories are supported by European Commission's Seventh Framework Programme under Mechanisms of the Development of Allergy (grant agreement no. 261357) and Post-infectious immune reprogramming and its association with persistence and chronicity of respiratory allergic diseases (grant agreement no. 260895), Swiss Polish Research Programme (grant no. PSPB-072/2010), and the Swiss National Science Foundation (grant no. 310030_156823).

Disclosure of potential conflict of interest: M. Jutel has received consultancy fees from Allergopharma, Biomay AG, Anergis, and the Polish National Science Centre, from which he has also received or has grants pending; he has received payment for delivering lectures from Stallergenes, GlaxoSmithKline, and Allergopharma as well as for the development of educational presentations from the Polish Society of Allergoplogy. C. A. Akdis has institutional ties to the Christine Kühne-Center for Allergy Research and Education and the European Academy of Allergy and Clinical Immunology. The rest of the authors declare that they have no relevant conflicts of interest.

\section{REFERENCES}

1. Lloyd CM, Saglani S. T cells in asthma: influences of genetics, environment, and T-cell plasticity. J Allergy Clin Immunol 2013;131:1267-74; quiz 75.

2. Jackson DJ, Sykes A, Mallia P, Johnston SL. Asthma exacerbations: origin, effect, and prevention. J Allergy Clin Immunol 2011;128:1165-74.

3. Akdis M, Akdis CA. Mechanisms of allergen-specific immunotherapy: multiple suppressor factors at work in immune tolerance to allergens. J Allergy Clin Immunol 2014;133:621-31.

4. Karagiannidis C, Akdis M, Holopainen P, Woolley NJ, Hense G, Ruckert B, et al Glucocorticoids upregulate FOXP3 expression and regulatory T cells in asthma. J Allergy Clin Immunol 2004;114:1425-33.

5. Purwar R, Campbell J, Murphy G, Richards WG, Clark RA, Kupper TS. Resident memory $\mathrm{T}$ cells $(\mathrm{T}(\mathrm{RM}))$ are abundant in human lung: diversity, function, and antigen specificity. PLoS One 2011;6:e16245.

6. Grzanka J, Leveson-Gower D, Golab K, Wang XJ, Marek-Trzonkowska N, Krzystyniak A, et al. FoxP3, Helios, and SATB1: roles and relationships in regulatory T cells. Int Immunopharmacol 2013;16:343-7.

7. Akdis M, Burgler S, Crameri R, Eiwegger T, Fujita H, Gomez E, et al. Interleukins, from 1 to 37, and interferon-gamma: receptors, functions, and roles in diseases. J Allergy Clin Immunol 2011;127:701-21, e1-70.

8. Akdis M, Palomares O, van de Veen W, van Splunter M, Akdis CA. TH17 and TH22 cells: a confusion of antimicrobial response with tissue inflammation versus protection. J Allergy Clin Immunol 2012;129:1438-49; quiz 50-1.

9. Takahashi K, Hirose K, Kawashima S, Niwa Y, Wakashin H, Iwata A, et al. IL-22 attenuates IL-25 production by lung epithelial cells and inhibits antigen-induced eosinophilic airway inflammation. J Allergy Clin Immunol 2011;128:1067-76; e1-6.

Available online January 17, 2015. http://dx.doi.org/10.1016/j.jaci.2014.12.1866

\section{Prevention of allergic asthma through Der p 2 peptide vaccination}

\section{To the Editor:}

House dust mites (HDMs) are a major source of allergens that affect more than $50 \%$ of allergic patients. ${ }^{1-3}$ The 


\section{METHODS Subjects}

The study population consisted of 38 asthmatic patients diagnosed according to the Global Initiative for Asthma 2012 update. They were consecutively recruited from the outpatient's clinics at the Department of Pulmonary Disease, University Hospital, Krakow. The clinical characteristics of the study patients are presented in Table E1. The study participants were stratified into a stable asthma group $(n=21)$ if none had experienced an exacerbation or a respiratory tract infection within the 6-week period preceding the study and their baseline $\mathrm{FEV}_{1}$ was more than $70 \%$ of the predicted value on the visit day. Asthma exacerbation was defined according to the joint American Thoracic Society/European Respiratory Society statement on Asthma Control and Exacerbations, ${ }^{\mathrm{E} 1}$ and the study subjects $(\mathrm{n}=16)$ were recruited during their unscheduled or emergency visits and before their treatment modification. Asthmatic patients enrolled into exacerbation groups were complaining of shortness of breath, cough for at least 2 days, and a little or no improvement in symptoms was observed after rescue medication with beta-agonist. The severity grade of asthma exacerbation was classified as moderate, and there was no significant difference between viral and nonviral exacerbations in retrospective analysis after the screening of viruses was completed. None of the patients was treated with leukotriene-modifying drugs at the time of blood sampling. Only 4 subjects among the asthmatic group were treated with systemic glucocorticoids (Table E1). There was no significant effect of treatment with glucocorticoids on the frequencies of respective T-cell subsets analyzed in the present study (Fig E7). Subjects with asthma exacerbations were routinely screened for viral pathogens using nasal lavage samples. The method was based on PCR as published elsewhere. ${ }^{\mathrm{E} 2}$ This screening revealed the presence of respiratory viral pathogens in 9 of the asthmatic patients (Table E1). The patients gave informed consent to participate in the study, and official approval from the Jagiellonian University Ethics Committee was obtained (KBET/7/B/2010). Healthy volunteers were recruited for the control group from among the staff of the Swiss Institute for Allergy and Asthma Research. None of the control subjects had any allergic disorders or were taking any medications.

\section{PBMCs - Isolation and culture conditions}

Human PBMCs were separated from peripheral venous blood of asthmatic individuals and healthy volunteers using Ficoll-Hypaque (Sigma, St Louis, Mo) density-gradient centrifugation. PBMCs were cryopreserved and stored in liquid nitrogen until use. Cells were thawed and incubated at a density of 1 $\times 10^{6}$ per $\mathrm{mL}$ in 24 -well plates at $37^{\circ} \mathrm{C}$ and $5 \% \mathrm{CO}_{2}$ for 1.5 hours in RPMI 1640 supplemented with $2 \mathrm{mM}$ L-glutamine, $1 \%$ (v/v) nonessential amino acids and minimum essential medium vitamins solution, $1 \mathrm{mM}$ sodium pyruvate, $100 \mathrm{U} / \mathrm{mL}$ penicillin, $100 \mu \mathrm{g} / \mathrm{mL}$ streptomycin, $50 \mu \mathrm{g} / \mathrm{mL}$ kanamycin, $50 \mu \mathrm{M} \beta$-mercaptoethanol (all from Invitrogen, Basel, Switzerland), and 10\% (v/v) heat-inactivated FCS (Sigma). For intracellular cytokine determination, PBMCs were activated with $20 \mathrm{ng} / \mathrm{mL}$ PMA and 1 $\mu \mathrm{g} / \mathrm{mL}$ ionomycin for 4 hours in the presence of $10 \mu \mathrm{g} / \mathrm{mL}$ brefeldin A (all from Sigma).

\section{Staining and flow-cytometry analysis}

PBMCs with or without stimulation were washed with PBS and stained with Fixable Viability Dye eFluor780 (VDeF780; eBioscience, San Diego, Calif) to exclude nonviable cells. Cells were surface stained at $4^{\circ} \mathrm{C}$ in the dark for 30 minutes, and then fixed and permeabilized by FoxP3 Fix/Perm buffer set (Biolegend, San Diego, Calif) or Cytofix/Cytoperm kit (BD, San Diego, Calif) according to the manufacturer's protocol. Antibodies used for surface and intracellular staining included anti-CD3 (UCHT1; BD Horizon, San Diego, Calif), anti-CD4 (RPA-T4; Biolegend), anti-CD4 (T4; Beckman Coulter, Fullerton, Calif), anti-CD25 (BC96; Biolegend), anti-CD127 (IM19800U; Beckman Coulter), anti-CD197 (3D12; BD Pharmingen, San Diego, Calif), anti-FOXP3 (259D; Biolegend), anti-Helios (22F6; Biolegend), anti-IL-4 (8D4-8; BD Pharmingen), anti-IL-10 (JES3-9D7; Biolegend), anti-IL-17A (BL168; Biolegend), anti-IL-22 (22URTI; eBioscience), and anti-IFN- $\gamma$ (4S.B3; Biolegend), all conjugated with separate fluorochromes. Appropriate isotype controls were used to determine specific staining.

All data were acquired on Galios Flow Cytometer (Beckman Coulter), and their analysis was performed by using Kaluza Analysis Software (Beckman Coulter).

\section{Statistical analysis}

The Kruskall-Wallis test followed by Dunn post hoc test of multiple comparison and nonparametric correlation (Spearman) were used for statistical analysis, and a statistical error type I $P$ value of less than .05 was considered significant. All statistical analysis was performed with GraphPad Prism software (GraphPad Software, Inc, La Jolla, Calif).

\section{REFERENCES}

E1. Reddel HK, Taylor DR, Bateman ED, Boulet LP, Boushey HA, Busse WW, et al An official American Thoracic Society/European Respiratory Society statement: asthma control and exacerbations: standardizing endpoints for clinical asthma trials and clinical practice. Am J Respir Crit Care Med 2009;180:59-99.

E2. Pyrc K, Stozek K, Wojcik K, Gawron K, Zeglen S, Karolak W, et al. Use of sensitive, broad-spectrum molecular assays and human airway epithelium cultures for detection of respiratory pathogens. PLoS One 2012;7:e32582. 
A

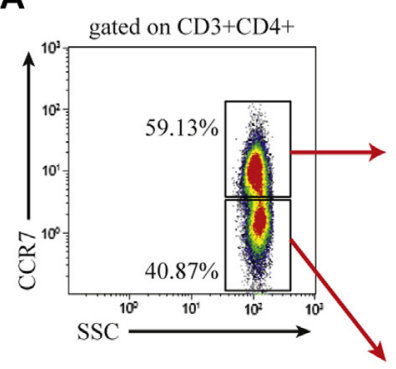

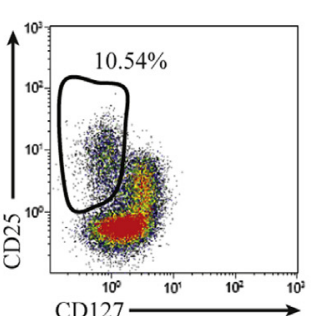

CD 127
B

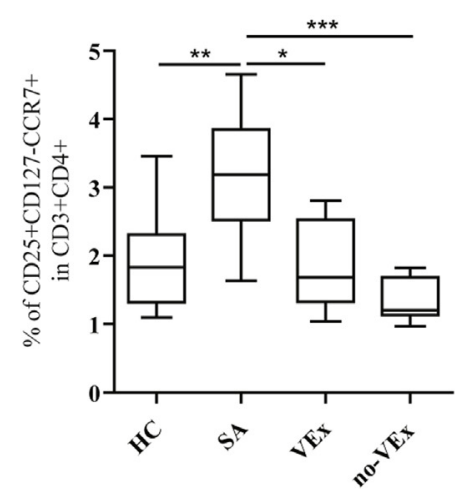

C

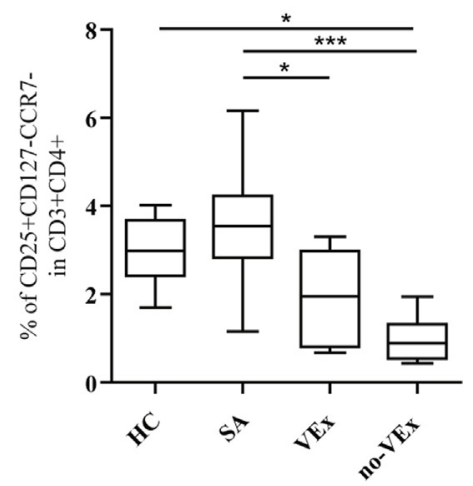

FIG E1. Subjects with asthma exacerbations show decreased frequencies of $\mathrm{CCR}^{+/-}$Treg cells than do subjects in the stable asthma group. A, Representative dot plots for classification of Treg cells according to expression of CCR7. The $\mathrm{CD}^{+}{ }^{+} \mathrm{CD} 4^{+}$population was distinguished between $\mathrm{CCR}^{+}$and $\mathrm{CCR}^{-}{ }^{-}$subsets and subsequently in each of these populations, Treg cells were identified on the basis of the expression of $\mathrm{CD} 25$ and $\mathrm{CD} 127$. The frequencies of $\mathrm{CD} 25^{+} \mathrm{CD} 127^{-} \mathrm{CCR} 7^{+/-}$were presented as a percentage of the $\mathrm{CD}^{+} \mathrm{CD}^{+}$population. B, Increased frequency of $\mathrm{CCR}^{+}$Treg cells in subjects with stable asthma. C, Subjects with asthma exacerbations exhibit decreased frequency of CCR7 ${ }^{-}$Treg cells than do subjects in the healthy control group and subjects with stable asthma. Differences with $P<.05$ were considered statistically significant. $H C$, Healthy control; $S A$, stable asthma; no-VEx, nonviral exacerbated asthma; VEX, viral exacerbated asthma. ${ }^{*} P \leq .05,{ }^{*} P \leq .01$, and ${ }^{*} * P \leq .001$. 

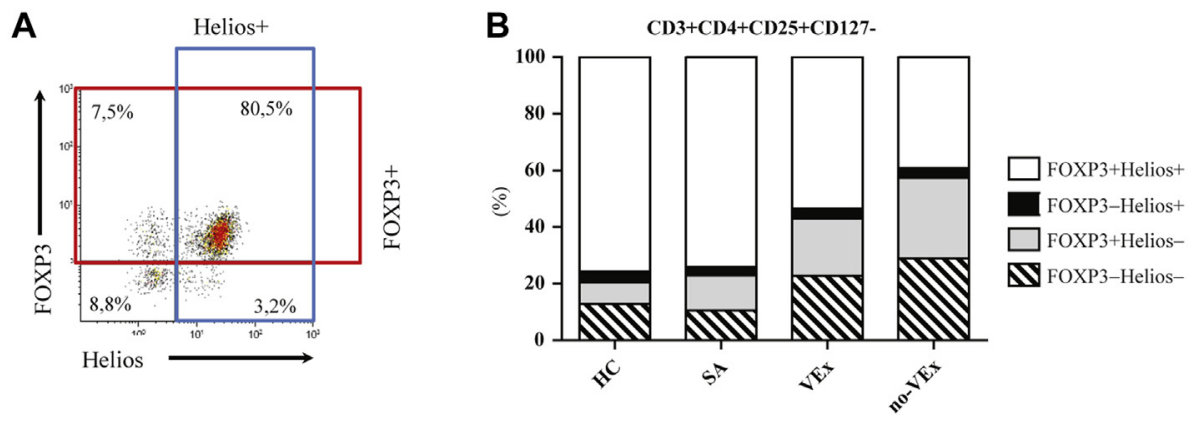

C

CD3+CD4+CD25+CD127-

D
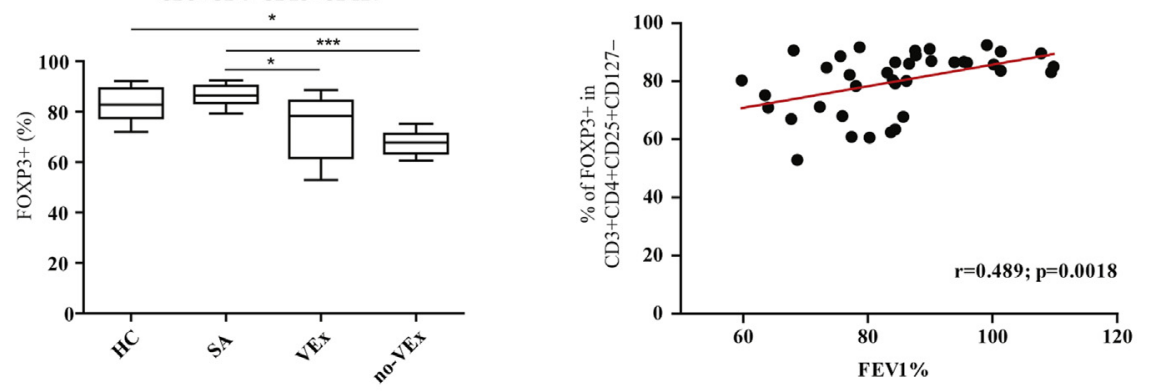

E

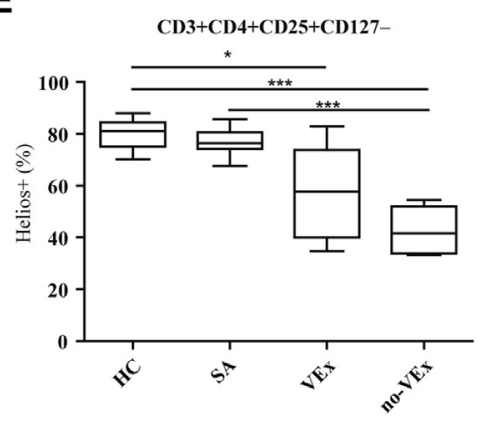

F

G
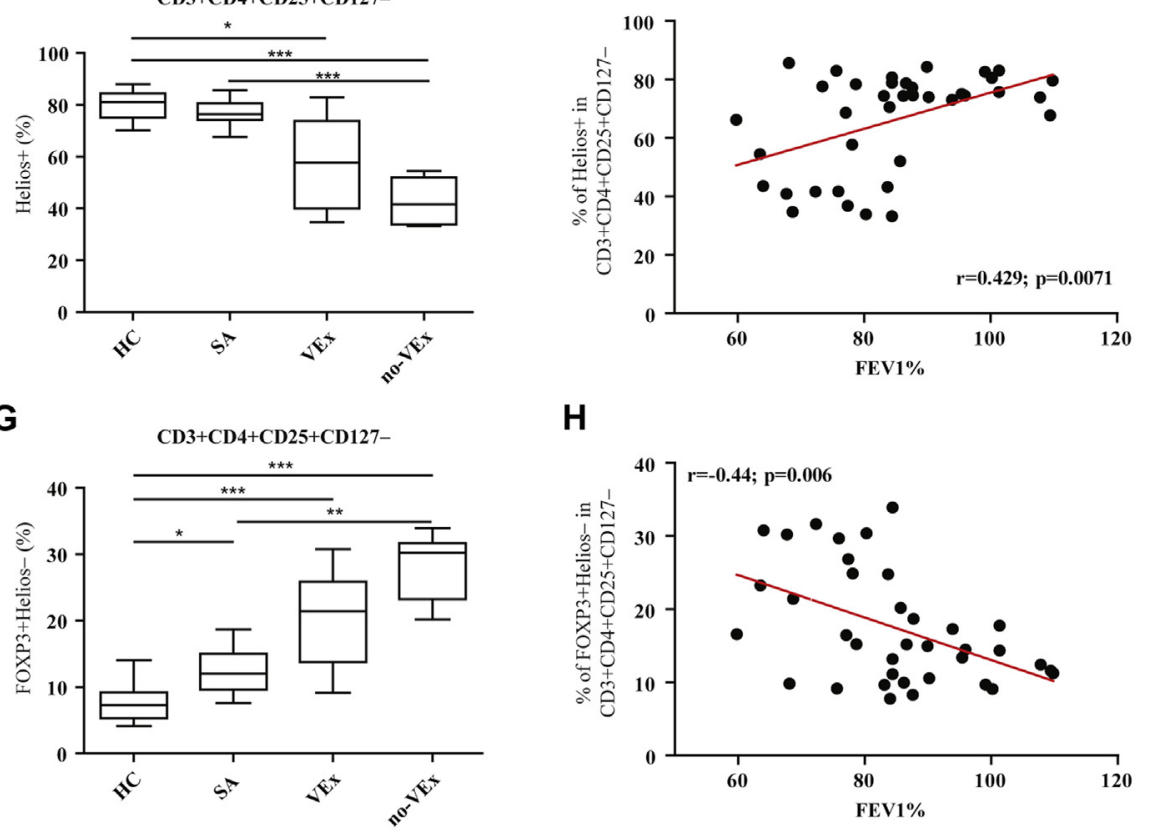

H

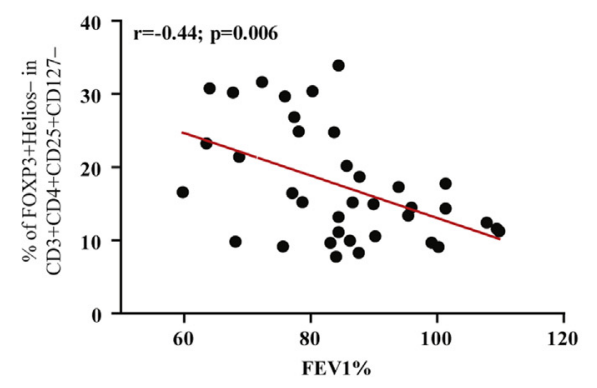

I

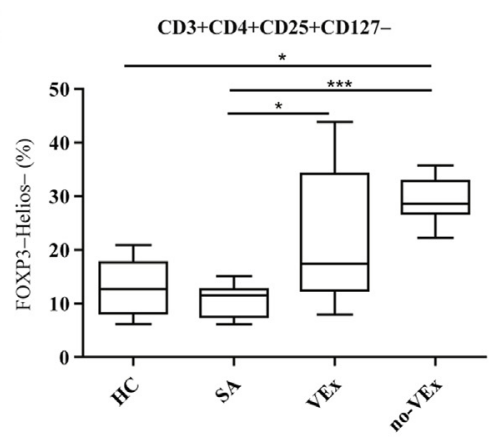

J

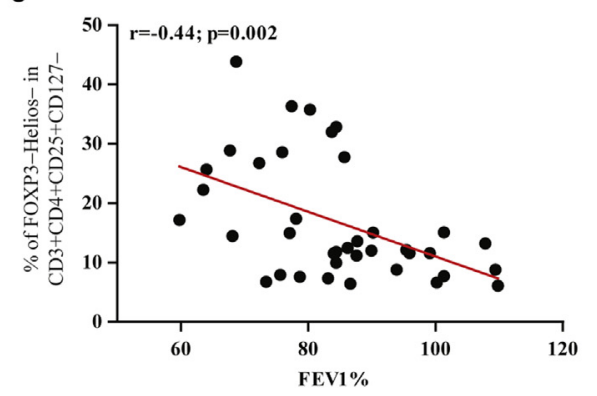


A

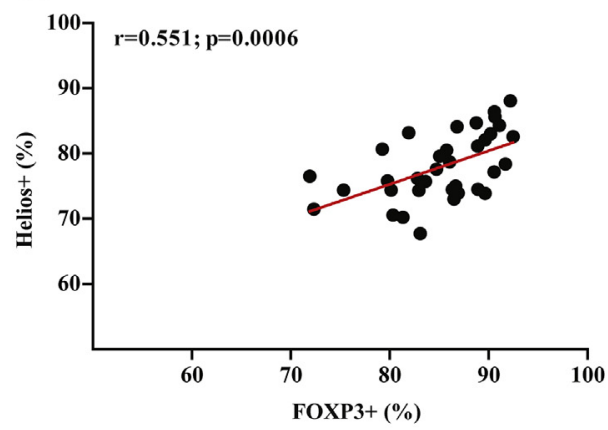

B

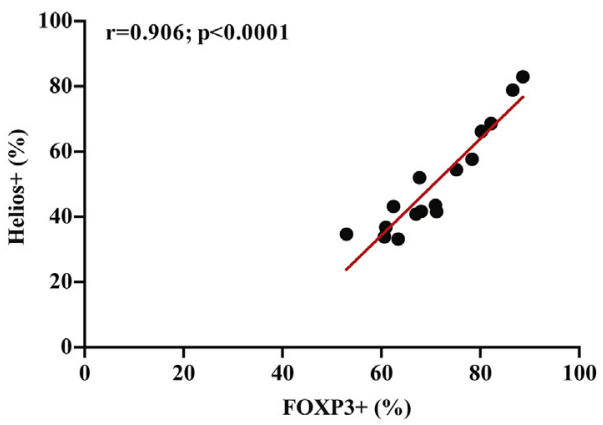

FIG E3. Correlation between the expressions of FOXP3 and Helios in Treg cells. The expression of FOXP3 was highly correlated with the expression of Helios both in subjects with stable asthma and healthy controls (A) and in subjects with asthma exacerbations (B).

FIG E2. Changes in the expression of transcription factors FOXP3 and Helios in Treg cells during asthma exacerbations. A, According to the expression of FOXP3 and Helios, Treg cells were divided into 4 distinct subsets (FOXP3 ${ }^{-} \mathrm{Helios}^{-}$, FOXP3 ${ }^{+} \mathrm{Helios}^{-}$, FOXP3 $^{+} \mathrm{Helios}^{+}$, and $\mathrm{FOXP3}^{-} \mathrm{Helios}^{+}$). Treg cells positive for FOXP3 $\left(\mathrm{FOXP3}^{+}\right.$) were a combination of $\mathrm{FOXP3}^{+} \mathrm{Helios}^{-}$and $\mathrm{FOXP3}^{+} \mathrm{Helios}^{+}$populations. Treg cells positive for Helios $\left(\mathrm{Helios}^{+}\right.$) consisted of FOXP3 ${ }^{-} \mathrm{Helios}^{+}$and FOXP3 ${ }^{+} \mathrm{Helios}^{+}$cells. B, Most of the Treg cells in healthy controls and in subjects with stable asthma were FOXP3 ${ }^{+} \mathrm{Helios}^{+}$, whereas during asthma exacerbations a reduction in the number of FOXP3 ${ }^{+} \mathrm{Helios}^{+}$and an increased frequency of FOXP3 ${ }^{+} \mathrm{Helios}^{-}$ and FOXP3 ${ }^{-}$Helios $^{-}$Treg cells were observed. The percentage of FOXP3 ${ }^{+}$Treg cells was reduced in asthma exacerbations (C) and was positively correlated with FEV1\% (D). The frequency of Helios ${ }^{+}$Treg cells was $^{-1}$ decreased in asthma exacerbations (E) and was positively correlated with $F E V_{1} \%$ (F). Asthma exacerbations

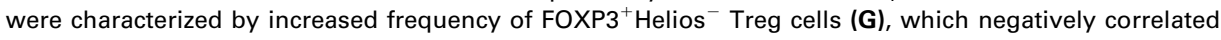
with $\mathrm{FEV}_{1} \%$ (H). Increased frequency of Treg cells negative for both FOXP3 and Helios was observed in asthma exacerbations (I) and was negatively correlated with $\mathrm{FEV}_{1} \%$ (J). Differences of $P<.05$ were considered statistically significant. $H C$, Healthy control; $S A$, stable asthma; no-VEx, nonviral exacerbated asthma; VEx, viral exacerbated asthma. ${ }^{*} P \leq .05,{ }^{*} P \leq .01$, and ${ }^{*}{ }^{*} P \leq .001$. 

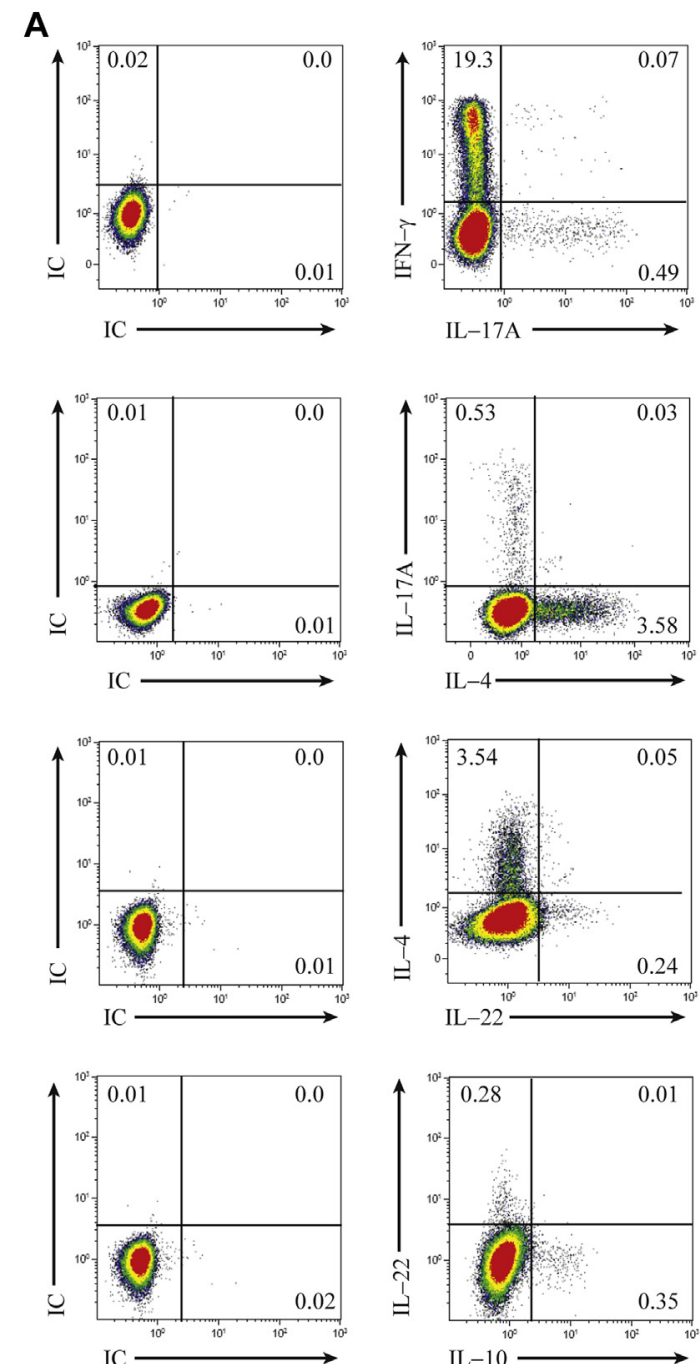
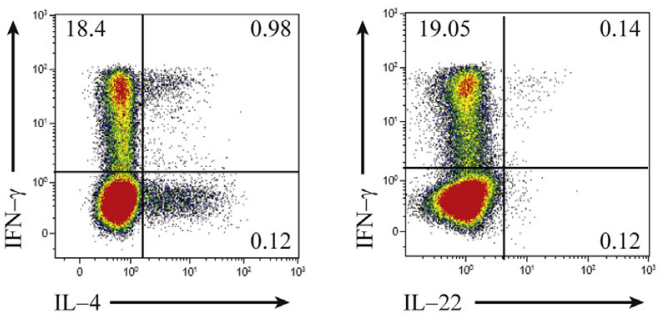

IL-22
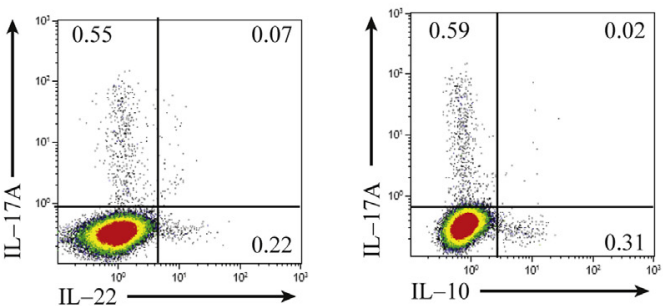

IL-10

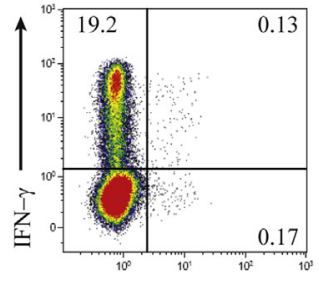

IL-10

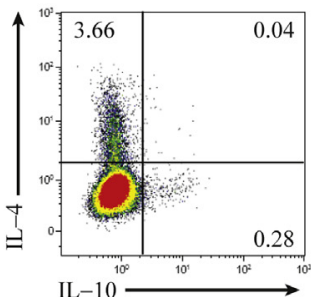

FIG E4. Flow-cytometric evaluation of the production of IL-4, IL-10, IL-17A, IL-22, and IFN- $\gamma$ by peripheral blood $\mathrm{CD}^{+} \mathrm{CD}^{+} \mathrm{T}$ cells. PBMCs were stimulated with PMA and ionomycin in the presence of brefeldin $A$, and the cytokine expression was analyzed by intracellular staining of $\mathrm{CD} 3^{+} \mathrm{CD} 4^{+} \mathrm{T}$ cells. A, The representative dot plots for cytokine-producing $\mathrm{CD}^{+} \mathrm{CD}^{+} \mathrm{T}$ cells are presented. PMA, Phorbol 12-myristate 13-acetate. 
A

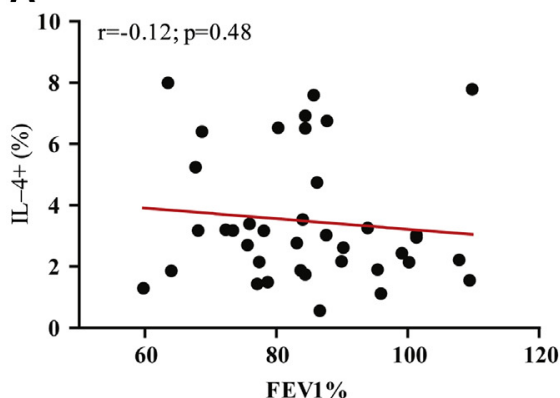

C

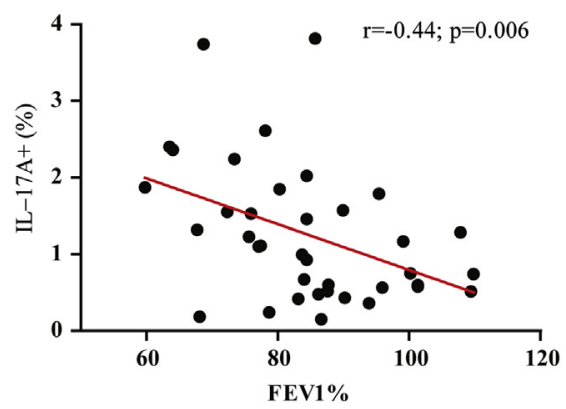

E

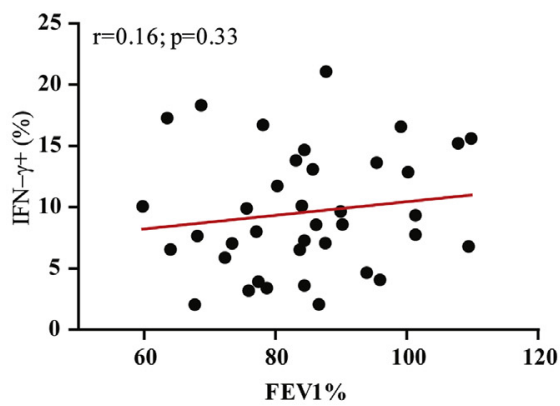

B

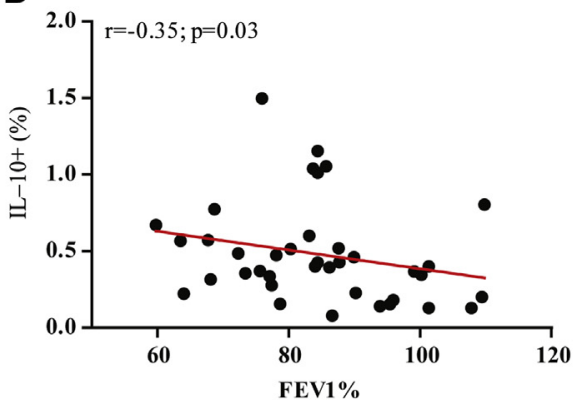

D

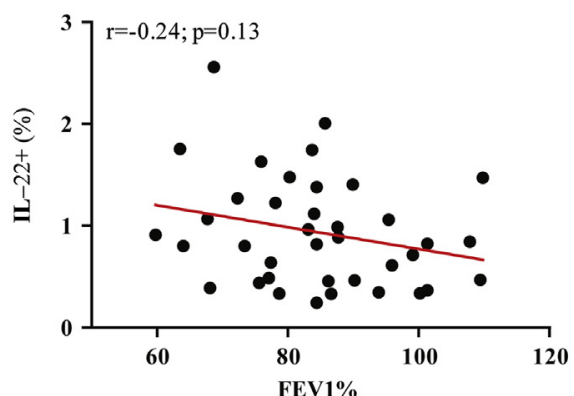

FIG E5. The frequency of IL-17A-producing cells negatively correlates with $\mathrm{FEV}_{1} \%$. The correlation between cytokine-producing $\mathrm{CD}^{+}{ }^{+} \mathrm{CD} 4^{+} \mathrm{T}$ cells and $\mathrm{FEV}_{1} \%$ was determined. A, There was no correlation between IL-4-producing $\mathrm{CD}^{+} \mathrm{CD}^{+} \mathrm{T}$ cells and $\mathrm{FEV} \mathrm{V}_{1} \%$. B, The percentage of IL-10-producing $\mathrm{CD}^{+} \mathrm{CD}^{+}$ $\mathrm{T}$ cells was negatively correlated with $\mathrm{FEV}_{1} \%$. C, Negative correlation to $\mathrm{FEV}_{1} \%$ was shown by $\mathrm{IL}-17 \mathrm{~A}$-producing $\mathrm{CD}^{+} \mathrm{CD}^{+} \mathrm{T}$ cells. No correlation between $\mathrm{FEV}_{1} \%$ and the percentages of IL-22-producing (D) and between $\mathrm{FEV}_{1} \%$ and the percentages of IFN- $\gamma$-producing $\mathrm{CD}^{+} \mathrm{CD}^{+}{ }^{+} \mathrm{T}_{\text {cells }}$ (E) was observed. 


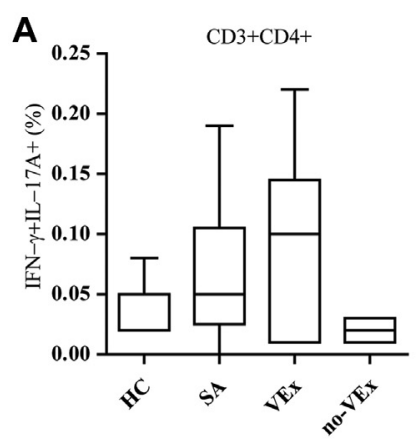

E

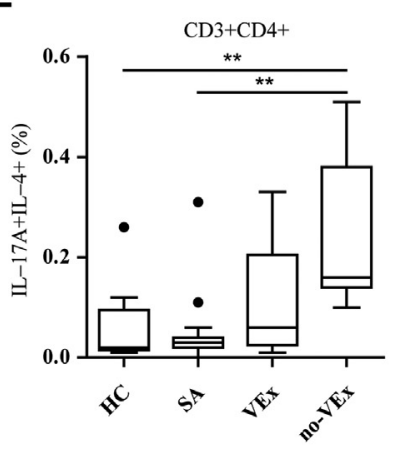

H

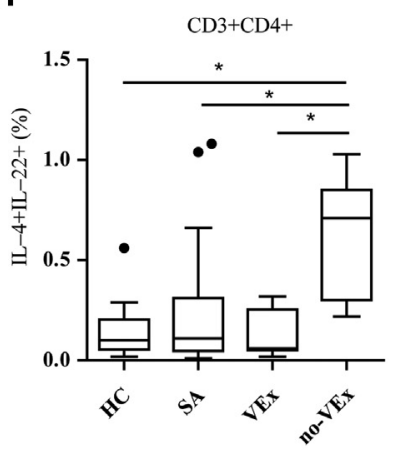

J

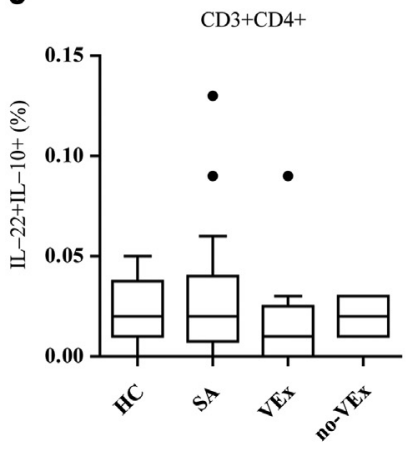

B

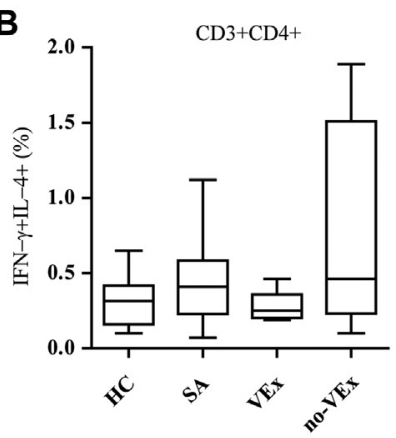

$\mathbf{F}$

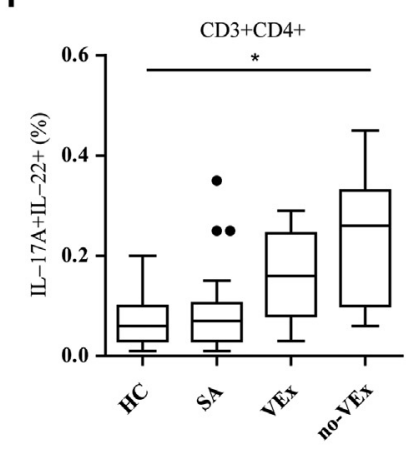

I

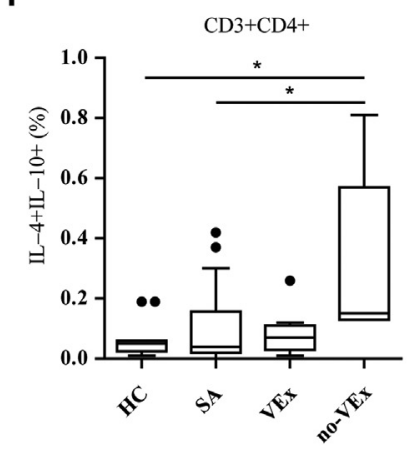

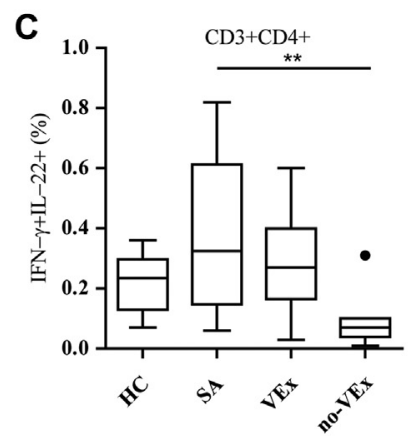

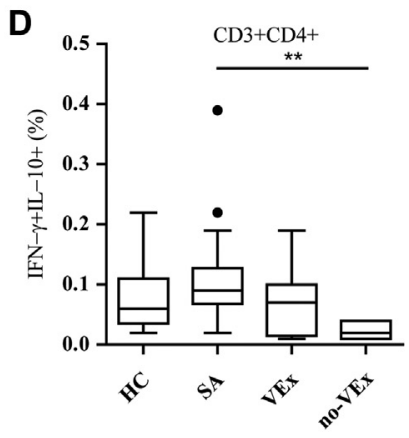

G

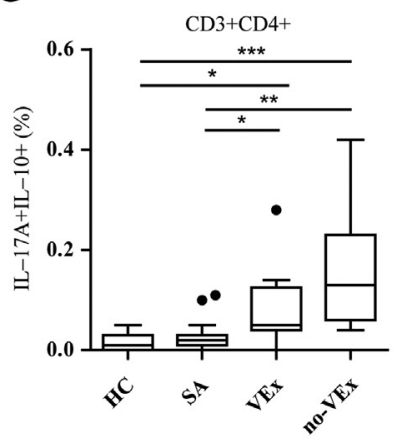

FIG E6. The cytokine profile of $\mathrm{CD}^{+} \mathrm{CD}^{+} \mathrm{T}$ cells. IFN- $\gamma$-producing $\mathrm{CD} 3^{+} \mathrm{CD} 4^{+} \mathrm{T}$ cells were able to coproduce IL-17A (A), IL-4 (B), IL-22 (C), and IL-10 (D). IL-17A-producing CD3 ${ }^{+} \mathrm{CD}^{+}{ }^{+}$T cells coexpress IL-4 (E), IL-22 (F), and IL-10 (G). IL-4-producing $\mathrm{CD}^{+} \mathrm{CD}^{+} \mathrm{T}$ cells were able to coexpress IL-22 (H) and IL-10 (I). J, IL-22 and IL-10-producing $\mathrm{CD}^{+}{ }^{+} \mathrm{CD} 4^{+} \mathrm{T}$ cells were detected. HC, Healthy control; SA, stable asthma; no-VEx, nonviral exacerbated asthma; VEX, viral exacerbated asthma. ${ }^{*} P \leq .05,{ }^{*} P \leq .01$, and ${ }^{* * *} P \leq .001$. 

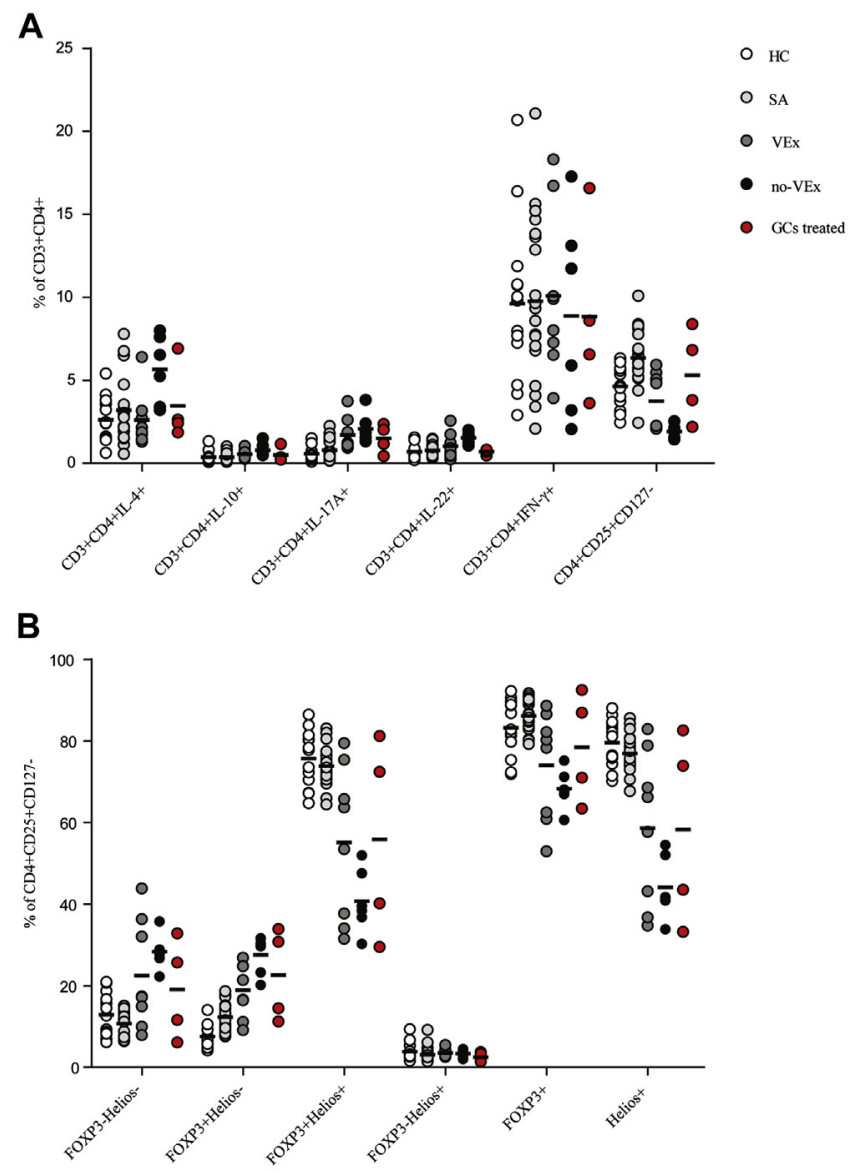

FIG E7. The impact of systemic glucocorticoid (GC) treatment on Treg cells and the cytokine profile of T cells. Subjects treated with systemic GCs ( $n=4)$ were analyzed separately and compared with other asthmatic groups. Two of them were among stable asthma subjects and the other 2 among subjects with exacerbated asthma (viral exacerbated asthma, $\mathrm{n}=1$, and nonviral exacerbated asthma, $n=1$ ). $A$, The prevalence of $T$ cells producing IL-4, IL-10, IL-22, and IFN- $\gamma$ in subjects treated with GCs did not differ from the control group and subjects with stable asthma. Subjects treated with systemic GCs have shown a tendency to increased frequency of $\mathrm{CD}^{+} \mathrm{CD}^{+}{ }^{+} \mathrm{LL}-17 \mathrm{~A}^{+} \mathrm{T}$ cells. B, Subjects treated with GCs showed heterogeneity for Treg-cell populations. Subjects treated with systemic GCs showed diversity with 2 low and 2 high expressions of FOXP3 and Helios. The reasons for this remain to be further analyzed. There was no difference between the control group and subjects with stable asthma as well as those with asthma exacerbations in analyzed parameters. $H C$, Healthy control; $S A$, stable asthma; no-VEx, nonviral exacerbated asthma; VEX, viral exacerbated asthma. 
TABLE E1. Characteristics of study subjects

Characteristic

n

Sex: male/female

Age (y), mean $\pm \mathrm{SD}$

Duration of asthma (y), mean $\pm \mathrm{SD}$

Total serum IgE (kU/dL), median (IQR)

Peripheral blood eosinophilia

(cells per $\mathrm{mm}^{3}$ ), median (IQR)

$\mathrm{FEV}_{1} \%$

Hypersensitivity to nonsteroidal

anti-inflammatory drugs, $\%$

Chronic rhinosinusitis, \%

Positive skin test results with common allergens, \%

GINA asthma severity, median (IQR)

Inhalatory corticosteroids (\%, average
Oral corticosteroids ( $\%$, average dose $\mathrm{mg}$ ) dose $\mu \mathrm{g}$, [range])
Stable asthma

Viral exacerbated asthma*

Nonviral exacerbated asthma Healthy controls

\section{1}

$5 / 16$

$44.77 \pm 13.75$

$12.82 \pm 14.57$

$67.0(24.0-191)$

364 (140-518)

$91.55 \pm 11.10$

59.1

95.5

40.1

$2(1-3)$

$9.0,16$

86.4, 500 (200-1000)

$2(1-3)$

7

$3 / 4$

$59.57 \pm 7.76$

$14.29 \pm 15.63$

411 (203-598)

426 (199-630)

$75.68 \pm 8.38$

42.9

57.1

71

4 (2-4)

$14.3,4$

100,1000 (500-1800)

9

$40.56 \pm 13.57$

$10.44 \pm 8.47$

71 (35-298)

$240(82-502)$

$74.31 \pm 8.45$

66.7

88.9

33.3

$11.1,8$

88.9, 960 (560-1000)

23 (16-25)
$17(8-21)$

Oral corticosteroids recalculated for methylprednisolone equivalent; inhaled corticosteroids recalculated for fluticasone equivalent.

$I Q R$, Interquartile range; $F E V_{1} \%$, predicted percentage of $\mathrm{FEV}_{1}$; GINA, Global Initiative for Asthma; NA, not applicable/available

*Viruses detected in the induced sputum during exacerbation were human: rhinovirus $(\mathrm{n}=6)$, metapneumovirus $(\mathrm{n}=1)$, parainfluenza-2 virus and metapneumovirus $(\mathrm{n}=1)$, and parainfluenza-1 and respiratory syncytial $(\mathrm{n}=1)$, as described in Pyrc et al. ${ }^{\mathrm{E} 2}$ 